УДК 697.329:006.354

\title{
ИМИТАЦИОННЫЕ МОДЕЛИ ВЕТРОЭНЕРГЕТИЧЕСКИХ УСТАНОВОК ВЗАИМОДЕЙСТВУЮЩИХ С ЭНЕРГОСИСТЕМОЙ
}

\author{
Андрианова Людмила Прокопьевна \\ д-р техн. наук, профессор \\ Байбурин Эдуард Рамилевич \\ канд. техн. наук, доцент \\ Уфимский государственный нефтяной \\ технический университет
}

Аннотация. В работе представлен систематизированный материал по принципам построения имитационных моделей ветроэнергетических установок (ВЭУ), присоединенных к энергосистеме. Приведены структуры, основные электрические и механические компоненты основных типов ВЭУ, входящих в энергосистему. Приведена обобщенная модульная структура модели ВЭУ, построенная на основе взаимосвязи между моделями ВЭУ, энергосистемы и ветроэлектростанций (ВЭС). Приведены общие параметры ВЭУ, переменные параметры начального состояния моделей ВЭУ, структурные схемы имитационных моделей для всех типов ВЭУ, а также виды параметров моделей модулей для каждого типа ВЭУ. Имитационные модели предназначены для оценки влияния работы ВЭУ на энергосистему, для оценки качества функционирования ВЭУ при возникновении возмущений в энергосистеме и отклонении параметров ВЭС при воздействии внешних климатических факторов.

Ключевые слова: ветроэнергетические установки, электрические и механические компоненты, общие параметры, имитационные модели, структуры и модули имитационных моделей, параметры моделей и модулей.

\section{SIMULATION MODELS OF WIND POWER PLANTS INTERACTING WITH THE POWER SYSTEM}

Andrianova Lyudmila Prokopyevna

Doctor of Technical Sciences, Professor Baiburin Eduard Ramilevich Candidate of Technical Sciences, Associate Professor

\footnotetext{
Abstract. The paper presents a systematic material on the principles of building simulation models of wind power plants (wind turbines) connected to the
} 
power system. The structures, the main electrical and mechanical components of the main types of wind turbines included in the power system are given. A generalized modular structure of the wind turbine model is presented, based on the relationship between the models of wind turbines, power systems, and wind farms. The general parameters of the wind turbine, variable parameters of the initial state of the wind turbine models, block diagrams of simulation models for all types of wind turbines, as well as the types of parameters of the module models for each type of wind turbine are given. Simulation models are designed to assess the impact of the wind turbine operation on the power system, to assess the quality of the wind turbine operation in the event of disturbances in the power system and the deviation of the wind turbine parameters under the influence of external climatic factors.

Key words: wind power plants, electrical and mechanical components, general parameters, simulation models, structures and modules of simulation models, parameters of models and modules.

Ветроэнергетические установки (ВЭУ), используемые для работы в энергосистемах, подразделяют на четыре типа [1-5]:

1) ВЭУ типа 1 с асинхронным генератором, непосредственно подключаемым к энергосистеме, с короткозамкнутым ротором и постоянным сопротивлением;

2) ВЭУ типа 2 с асинхронным генератором, непосредственно подключаемым к энергосистеме с переменным сопротивлением ротора;

3) ВЭУ типа 3 с асинхронным генератором со статором, непосредственно подключаемым к энергосистеме, и ротором, подключаемым через электронный преобразователь;

4) ВЭУ типа 4 с синхронным и асинхронным генератором, подключаемым к энергосистеме через электронный преобразователь.

«Общая имитационная модель ВЭУ (wind turbines generic simulation model): Имитационная модель, которая описывает один из типов ВЭУ и может быть настроена на имитацию различных вариантов ВЭУ этого типа с помощью изменения параметров модели» [4, с. 4].

Имитационные модели ВЭУ создают для оценки влияния работы ВЭУ на энергосистему, для оценки изменения выходных параметров ВЭУ при возникновении возмущений в энергосистеме и изменении параметров ветроэлектростанций (ВЭС) под воздействием других внешних факторов, например, скорости ветра. 
Взаимосвязь имитационной модели ВЭУ с имитационными моделями ВЭС и энергосистемы показана на рис. 1.

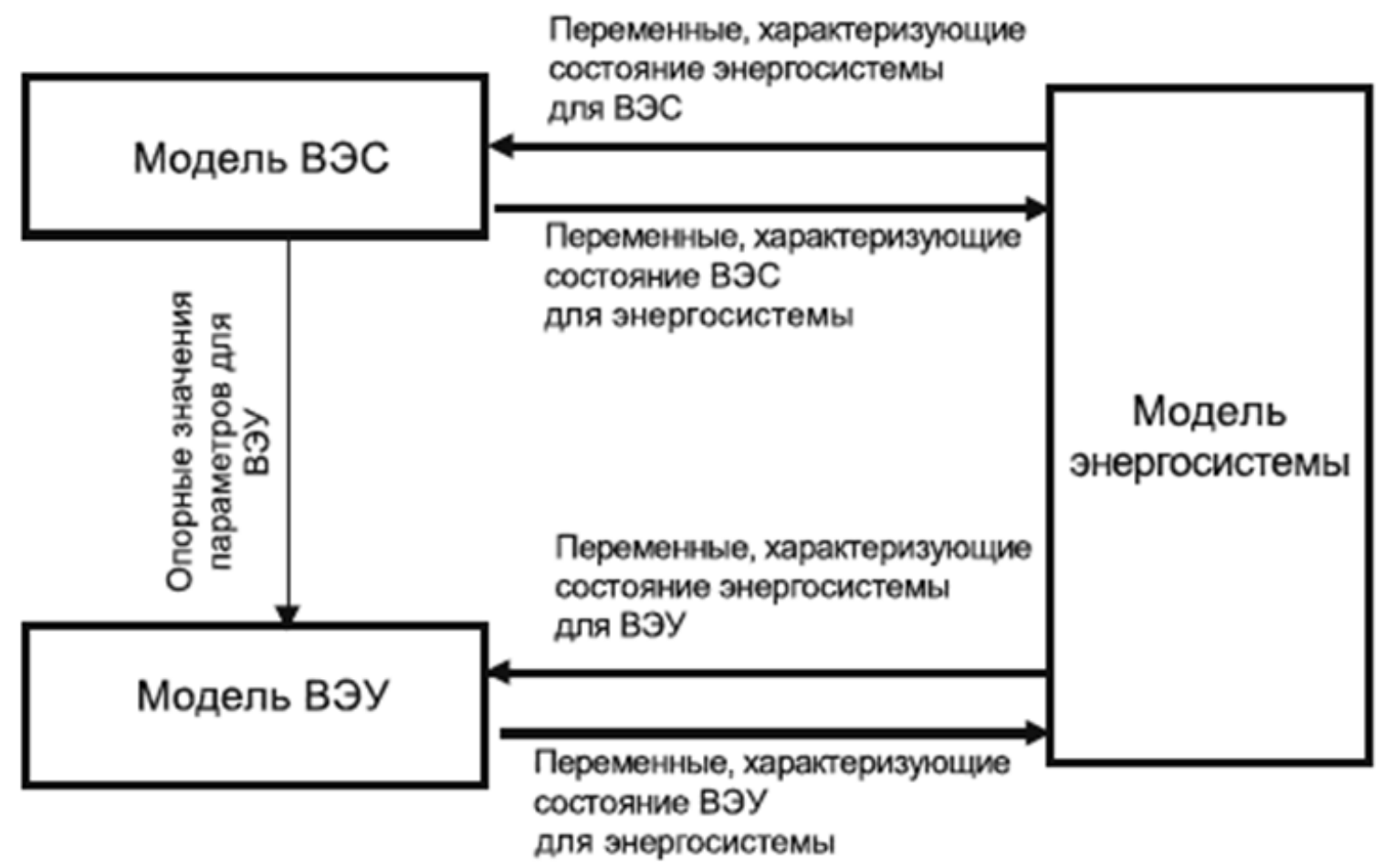

\section{Рис. 1. Взаимодействие между моделями ВЭУ, энергосистемы, и ВЭС [4, с.13]}

В качестве входных переменных, характеризующих состояние энергосистемы в данный момент времени, имитационная модель ВЭУ использует напряжения, выходными переменными модели ВЭУ являются токи, характеризующие состояние ВЭУ для энергосистемы.

Значения этих входных и выходных переменных определяют на выводах ВЭУ. «Моделирование может быть инициировано или событием в модели сети, таким как короткое замыкание, или изменением опорных значений параметров, задаваемых средствами управления ВЭС» [4, с.7] .

Набор опорных величин зависит от типа ВЭУ, изготовителя ВЭУ и рабочего режима. В обобщенных имитационных моделях ВЭУ используются опорные значения: активной и реактивной мощности, и напряжения.

Модели ВЭУ также могут воспроизводить режим регулирования коэффициента мощности, но в этом случае предполагается, что опорное значение коэффициента мощности ВЭУ является постоянным на протяжении всего моделирования. 
Параметры для каждого из модулей модели ВЭУ предоставляются изготовителем ВЭУ. В зависимости от того, чем определяется параметр, различают следующие параметры моделей модулей ВЭУ [3, 4]:

- механические и электрические параметры, зависящие от типа ВЭУ;

- параметры системы управления, зависящие от конкретного применения ВЭУ (от проекта) и работы ВЭУ в конкретной ВЭС;

- случайные параметры, зависящие от установившегося режима работы ВЭУ до возникновения переходного процесса, т.е. режима работы ВЭУ до поступления сигнала от системы электроснабжения или ВЭС предшествующего установившегося режима ВЭУ.

К случайным параметрам общих моделей ВЭУ относятся [4]:

- начальный угол установки лопастей, [ $\Theta$, град.], (однопараметрическая аэродинамическая модель аэродинамического модуля ВЭУ типов $3 \mathrm{~A}, 3 \mathrm{~B}$ );

- доступная аэродинамическая мощность $\left[P_{\text {aero }}\right.$ (двухпараметрическая аэродинамическая модель аэродинамического модуля ВЭУ типа 3А);

- угол установки лопастей [ $\Theta$, град.], если номинальная мощность ВЭУ не понижена (двухпараметрическая аэродинамическая модель аэродинамического модуля ВЭУ типа $3 \mathrm{~A})$;

- длительности замыкания в зависимости от изменения напряжения (модель генератора ВЭУ типа 3В);

- постоянная времени сглаживающего фильтра замыкающего устройства (модель генератора ВЭУ типа 3В);

- режим управления замыкающего устройства (модель генератора ВЭУ типа 3В);

- смещение опорного значения, которое ограничивает действие регулятора при изменениях скорости вращения ротора генератора (модель регулирования активной мощности модуля управления ВЭУ типа 3);

- смещение опорного напряжения (модель регулирования реактивной мощности модуля управления ВЭУ типов 3А, 3В, 4А, 4В).

Общие параметры моделей ВЭУ указаны в таблице 1.

Таблица 1

Общие параметры моделей ВЭУ [4, с.15]

\begin{tabular}{|c|c|c|}
\hline Обозначение & Единица измерения & Описание \\
\hline$f_{\text {ном }}$ & Гц & Номинальная частота \\
\hline$T_{\mathrm{s}}$ & $\mathrm{c}$ & Шаг интегрирования по времени \\
\hline
\end{tabular}


Начальное состояние модели ВЭУ должно быть согласовано с начальными состояниями модели энергосистемы и модели ВЭС. Взаимосвязь начальных состояний энергосистемы, модели ВЭС и модели ВЭУ показана на puc. 2.

Перед инициализацией модели необходимо обновить параметры, зависящие от варианта построения сеанса моделирования (от установившегося режима ВЭУ до возникновения возмущения), а также параметры, определяемые потокораспределением мощности в модели энергосистемы и зависящие от варианта моделирования параметры ВЭУ и ВЭС. Модель энергосистемы приводится в начальное состояние параметрами потокораспределения мощности, которые должны быть заданы в соответствии с режимами управления в моделях ВЭС и ВЭУ. Эти параметры оказывают влияние на начальное состояние моделей ВЭС и ВЭУ, поскольку они определяют исходные напряжения и токи.

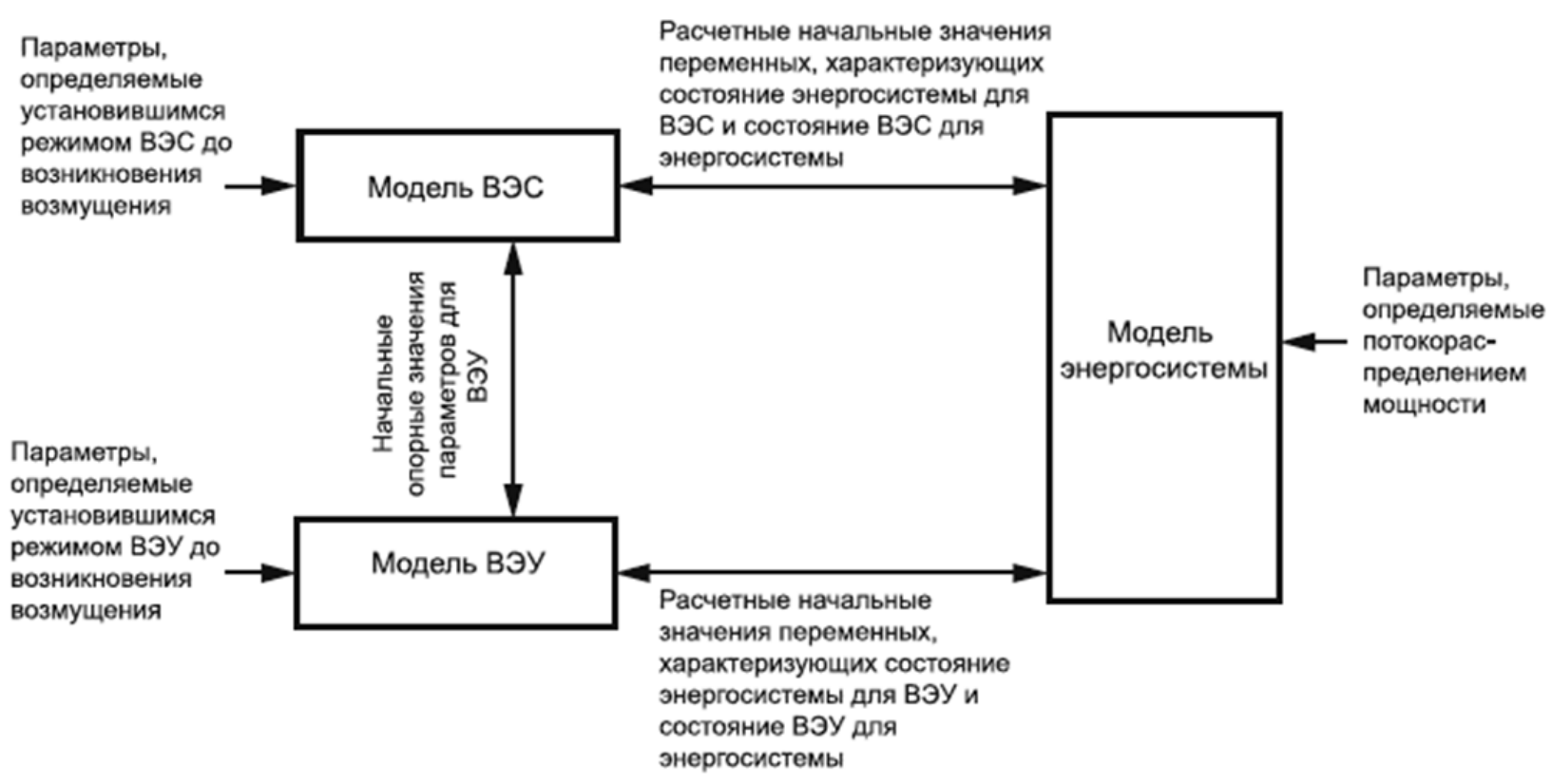

Рис. 2. Взаимосвязь начальных состояний моделей ВЭУ, ВЭС и энергосистемы $[4$, с. 16$]$

Кроме того, в зависимости от начальных значений опорных параметров начальное состояние модели ВЭС может оказывать влияние на начальное состояние модели ВЭУ.

Переменные начального состояния, используемые в моделях ВЭУ, приведены в таблице 2 . 
Таблица 2

\section{Переменные параметры начального состояния моделей ВЭУ [4, с. 16]}

\begin{tabular}{|c|c|l|}
\hline Параметр & Базисная величина & \multicolumn{1}{|c|}{ Описание } \\
\hline$P_{\text {init }}$ & $P_{\text {ном }}$ & Начальная активная мощность \\
\hline$\tau_{\text {init }}$ & $M_{\text {basc }}$ & Начальный стационарный момент трансмиссии \\
\hline $\operatorname{tg}\left(\varphi_{\text {init }}\right)$ & - & $\begin{array}{l}\text { Коэффициент пересчета реактивной мощности } \\
\text { по активной, используемый в регулировании } \\
\text { коэффициентом мощности }\end{array}$ \\
\hline
\end{tabular}

Основой построения моделей ВЭУ является модульный принцип. Обобщенная модульная структура моделей ВЭУ, соответствующая структуре взаимодействия модели ВЭУ с моделью энергосистемы и моделью ВЭС, изображенной на рис.1, представлена на рис. 3 .

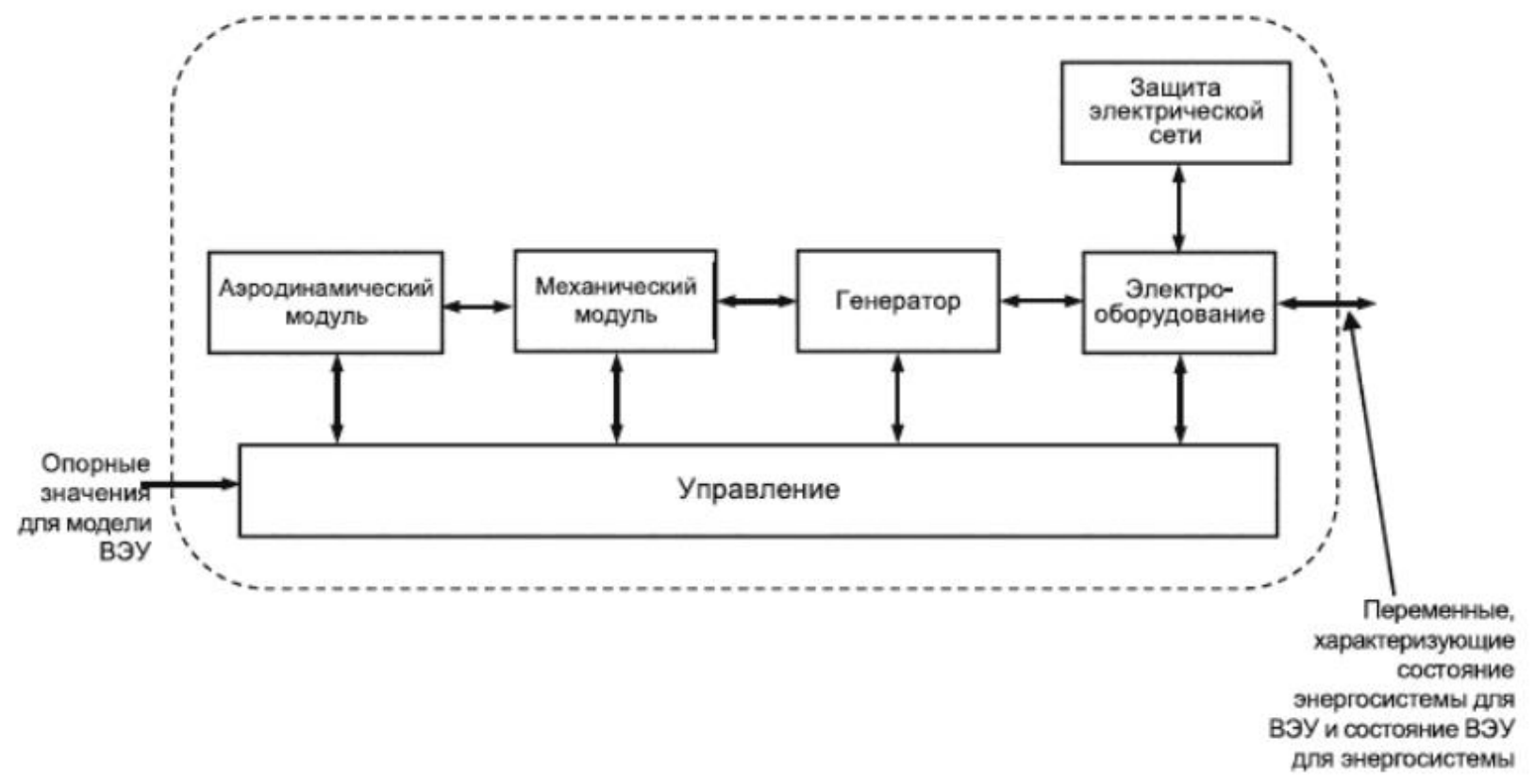

Рис. 3. Обобщенная структура моделей ВЭУ [4, с.16]

В горизонтальном ряду обобщенной структуры модели ВЭУ (рис. 3) расположены аэродинамический и механический модули, генератор и электрооборудование, отображающие преобразование аэродинамической мощности в электрическую мощность на выводах ВЭУ.

Модели ВЭУ типа 1. В ВЭУ типа 1 применяют асинхронные генераторы, непосредственно подключаемые к энергосистеме, т.е. не использующие преобразователи энергии. В большинстве ВЭУ типа 1 применяют системы 
легкого запуска, но они являются активными только при первоначальном пуске.

Основные электрические и механические компоненты, включаемые в модели ВЭУ типа 1, показаны на рис. 4.

Серым цветом на рис. 4 обозначены возможные компоненты ВЭУ типа 1.

Ветроколесо (ротор) ВЭУ соединено с асинхронным генератором через мультипликатор. Компенсацию реактивной мощности обеспечивает конденсаторная батарея. Большинство ВЭУ типа 1 оснащены конденсаторными батареями с механическим переключением, емкости которых при кратковременном моделировании считаются неизменяющимися.

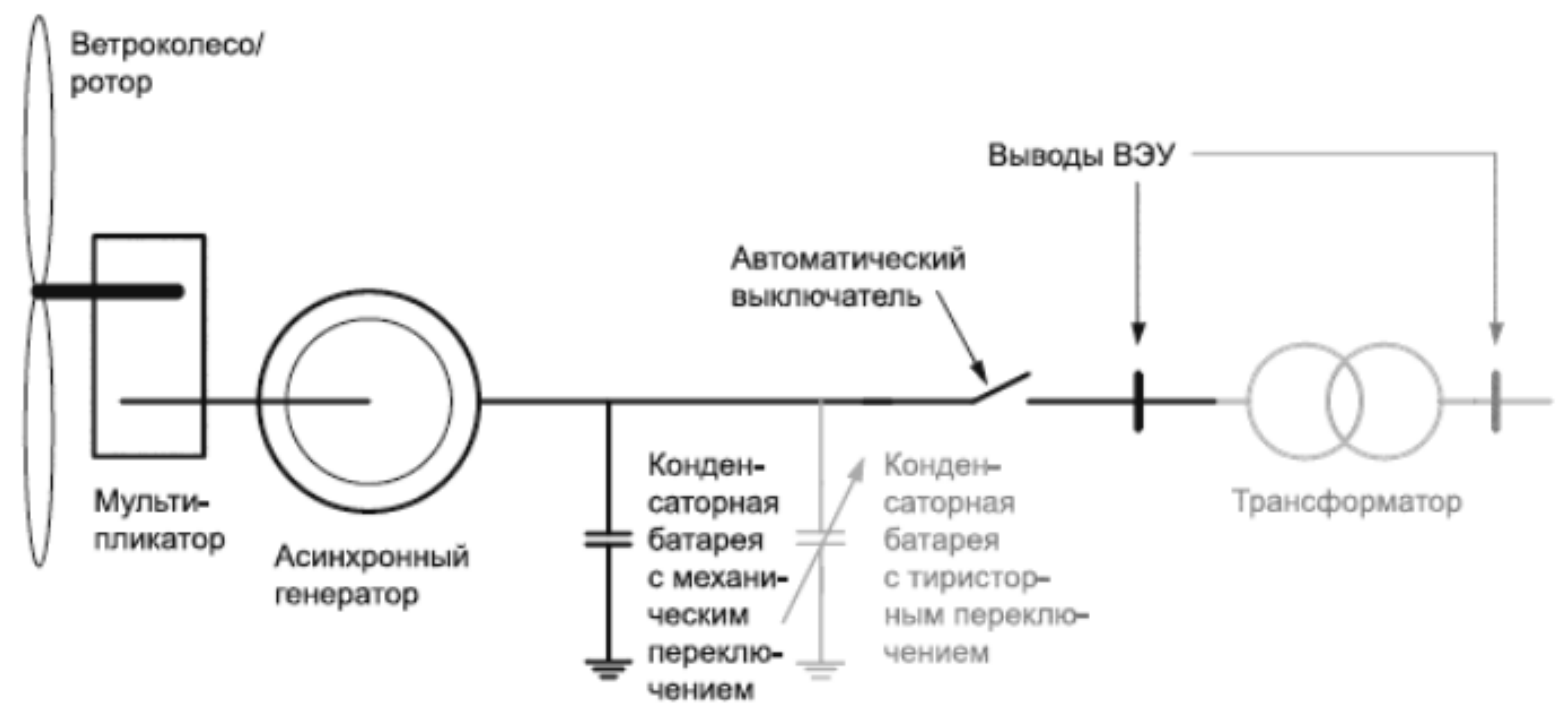

\section{Рис. 4. Электрические и механические} компоненты ВЭУ типа 1[4, с.17]

В ВЭУ типа 1 с защитой от провалов напряжения обычно используют конденсаторные батареи с тиристорным переключением, которые имеют динамическое управление во время и после возникновения неисправностей. Главный автоматический выключатель отсоединяет генератор и конденсаторы одновременно. Выводы ВЭУ могут располагаться как до, так и после трансформатора.

В ВЭУ типа 1 могут использоваться как ветроколесо (ротор) с постоянным углом установки лопастей, так и с управляемым углом установки лопастей, положение которых может как ослаблять аэродинамическое торможение (положительный угол установки), так и усиливать его (отрицательный угол установки, также называемый активным управлением мощностью или комбинированным управлением торможением). 
ВЭУ, в которых угол установки лопастей постоянный или управление им не используется для преодоления провалов напряжения, относятся к ВЭУ типа 1А. ВЭУ, в которых управление углом установки лопастей используют для преодоления провалов напряжения, относятся к ВЭУ типа $1 \mathrm{~B}$.

Структура модели ВЭУ типа 1 А с постоянным углом установки лопастей показана на рис. 5, а описание модулей приведено в таблице 3.

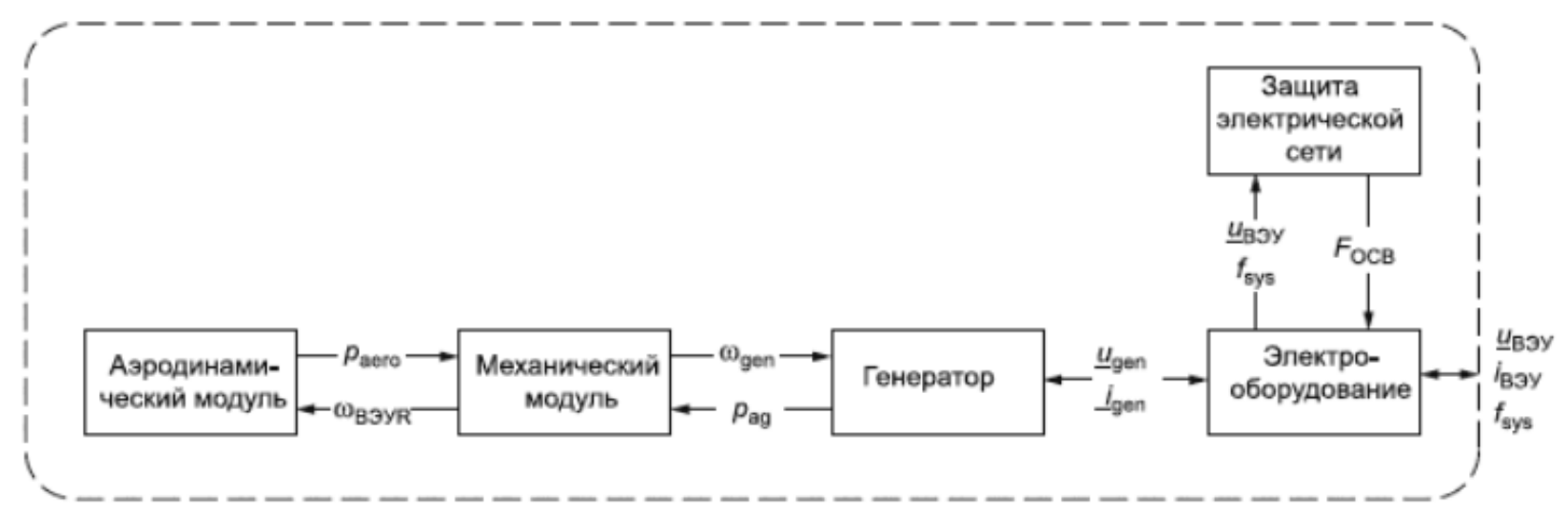

Рис. 5. Структура модели ВЭУ типа $1 \mathrm{~A}$

с постоянным углом установки лопастей [4, с.18]

Таблица 3

Модули модели ВЭУ типа 1А

с постоянным углом установки лопастей

\begin{tabular}{|l|l|}
\hline \multicolumn{1}{|c|}{ Модуль } & \multicolumn{1}{c|}{ Модели } \\
\hline Аэродинамический & Модель с постоянным аэродинамическим моментом \\
\hline Механический & Двухмассовая модель \\
\hline Генератор & Модель асинхронного генератора \\
\hline Электрооборудование & $\begin{array}{l}\text { Модель шунтирующего конденсатора } \\
\text { Модель автоматического выключателя } \\
\text { (Модель трансформатора) }\end{array}$ \\
\hline Защита электрической сети & Модель защиты электрической сети \\
\hline
\end{tabular}

Структура модели ВЭУ типа 1В с управлением углом установки лопастей для преодоления провалов напряжения показана на рис. 6, а описание модулей модели ВЭУ типа 1В приведено в таблице 4. 


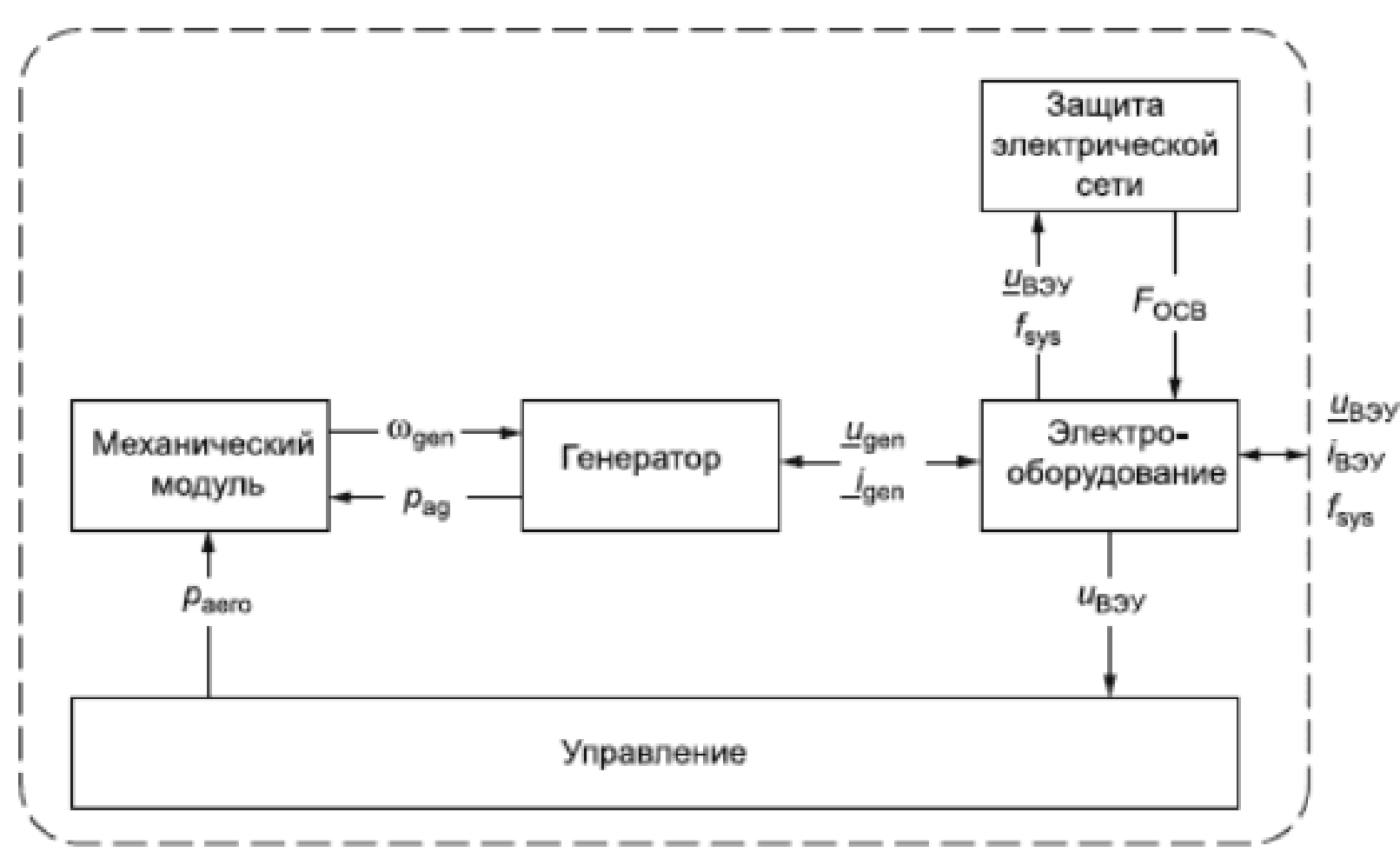

Рис.6. Структура модели ВЭУ

с управлением углом установки лопастей типа 1B [4, с. 19]

Таблица 4

Модули модели ВЭУ типа 1В

с управлением углом установки лопастей

\begin{tabular}{|c|c|}
\hline Модуль & Модели \\
\hline Механический & Двухмассовая модель \\
\hline Генератор & Модель асинхронного генератора \\
\hline Электрооборудование & \begin{tabular}{lc}
\multicolumn{1}{c}{ Модель } & шунтирующего \\
Модель & автоматического \\
(Модель трансформатора)
\end{tabular} \\
\hline Управление & $\begin{array}{c}\text { Модель регулирования мощности посредством } \\
\text { изменения угла установки лопастей } \\
\end{array}$ \\
\hline $\begin{array}{c}\text { Защита электрической } \\
\text { сети }\end{array}$ & Модель защиты электрической сети \\
\hline
\end{tabular}

На рис. 6 и в таблице 4 аэродинамический модуль отдельно не показан, так как в модели ВЭУ типа 1В аэродинамические процессы учтены в модуле управления. 
Модели ВЭУ типа 2. Структура модели ВЭУ типа 2 подобна ВЭУ типа 1, но в отличие от ВЭУ типа 1 в ВЭУ типа 2 используют асинхронные генераторы с переменным сопротивлением ротора. Кроме того ВЭУ типа 2 обычно снабжены управлением углом установки лопастей.

Основные электрические и механические компоненты, включаемые в модели ВЭУ типа 2, показаны на рис. 7.

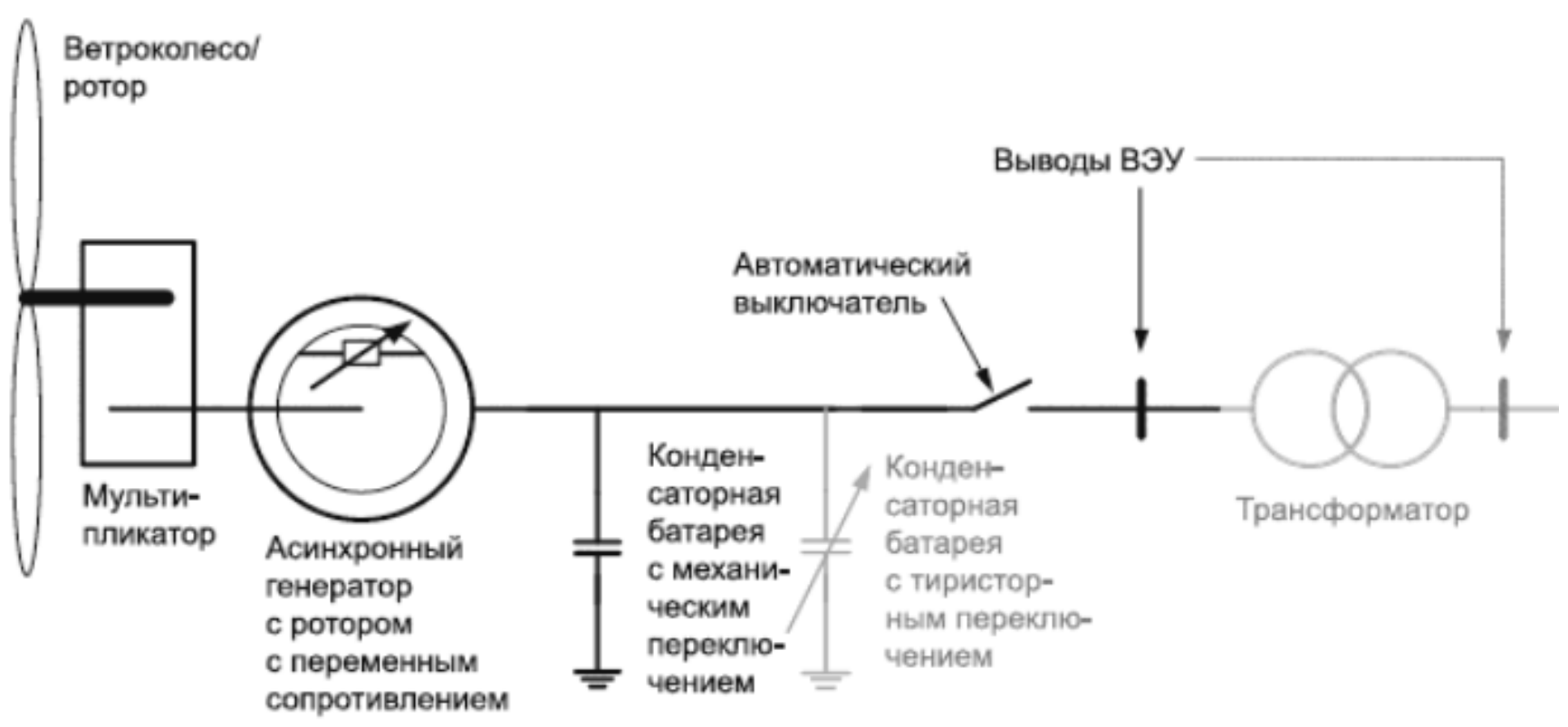

Рис. 7. Электрические и механические компоненты модели ВЭУ типа $2[4$, с.20]

Серым цветом на рис. 7 обозначены возможные компоненты ВЭУ типа 2.

Структура модели ВЭУ типа 2 показана на рис. 8, а описание модулей модели ВЭУ типа 2 приведено в таблице 5. 


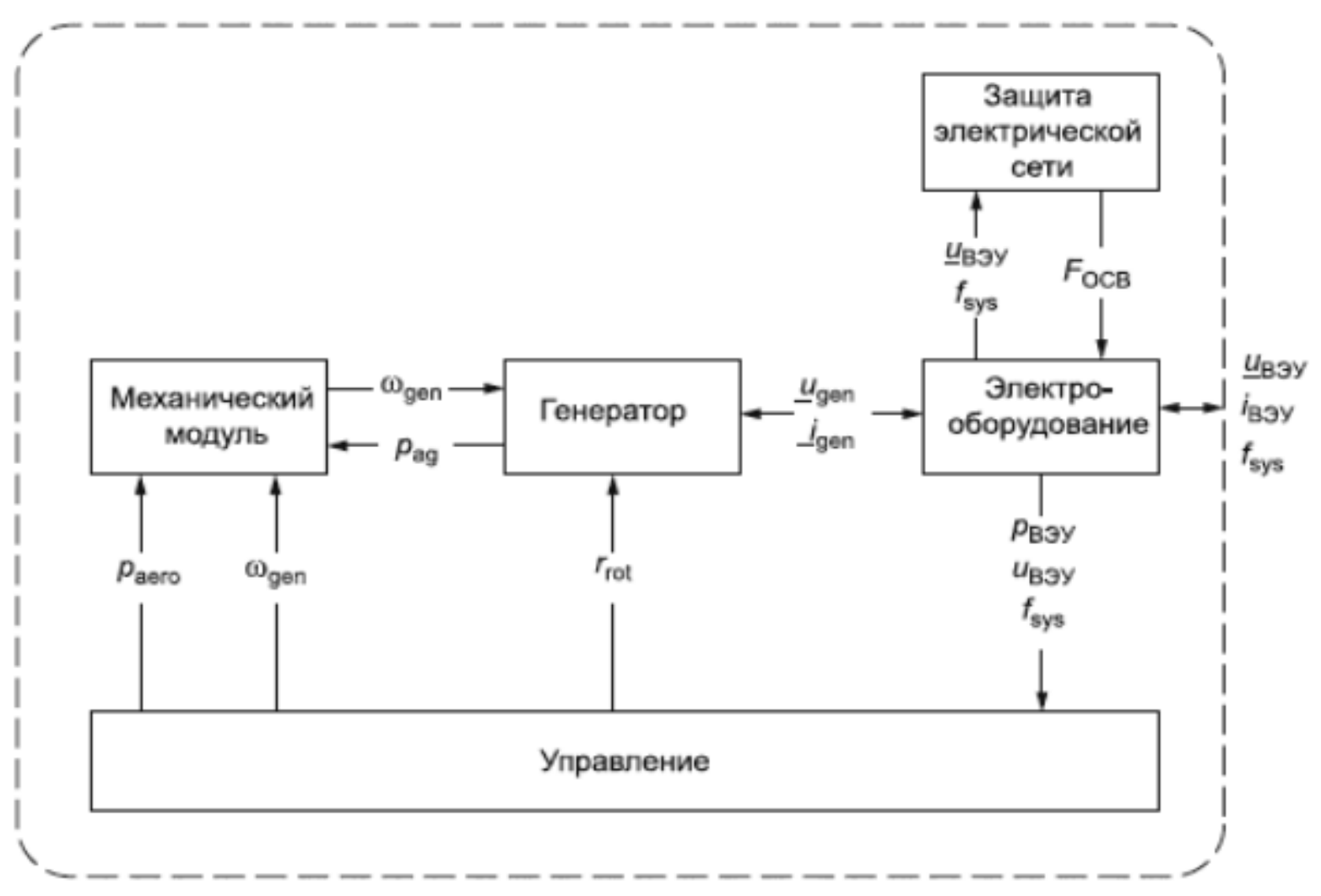

Рис. 8. Структура модели ВЭУ типа $2[4$, с.20]

Таблица 5

\section{Модули модели ВЭУ типа 2}

\begin{tabular}{|l|l|}
\hline \multicolumn{1}{|c|}{ Модуль } & \multicolumn{1}{c|}{ Модели } \\
\hline Механический & Двухмассовая модель \\
\hline Генератор & Модель асинхронного генератора \\
\hline Электрооборудование & $\begin{array}{l}\text { Модель шунтирующего конденсатора } \\
\text { Модель автоматического выключателя } \\
\text { (Модель трансформатора) }\end{array}$ \\
\hline Управление & $\begin{array}{l}\text { Модель регулирования мощности посредством } \\
\text { изменения угла установки лопастей } \\
\text { Модель регулирования сопротивления ротора } \\
\text { генератора }\end{array}$ \\
\hline Защита электрической сети & Модель защиты электрической сети \\
\hline
\end{tabular}

Отдельно аэродинамический модуль не показан на рис. 8 и в таблице 5, так как аэродинамические воздействия включены в модуль управления.

Структурная схема модуля управления для моделей ВЭУ типа 2 показана на рис. 9. Для регулирования активной мощности используется модель 
регулирования мощности посредством изменения угла установки лопастей совместно с моделью регулирования сопротивления ротора генератора, а опорная реактивная мощность или опорное напряжение $\left(x_{\text {ref }}\right)$ передается на модель шунтирующего конденсатора в модуле электрического оборудования.

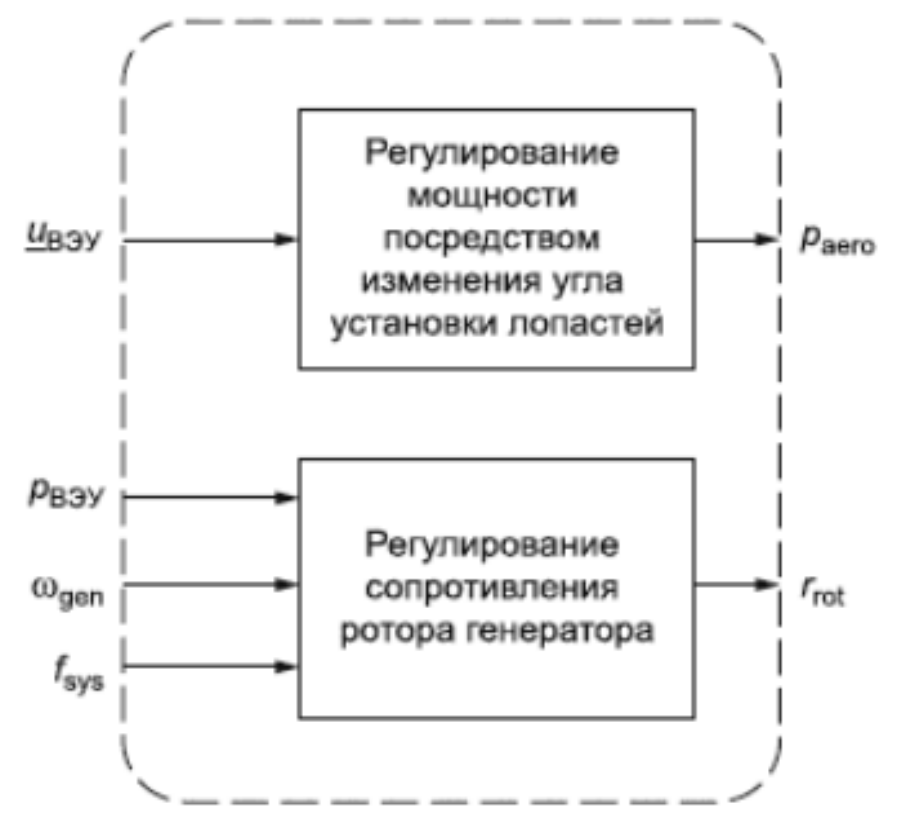

\section{Рис. 9. Структура модуля управления модели ВЭУ типа 2 [4, с.21]}

Модели ВЭУ типа 3. В ВЭУ типа 3 используется асинхронный генератор с двойным питанием, в котором статор подключается к энергосистеме непосредственно, а ротор - через промежуточный преобразователь. Основные электрические и механические компоненты модели ВЭУ типа 3 показаны на рис. 10, где серым цветом обозначены возможные компоненты ВЭУ типа 3.

Преобразователь состоит из преобразователя на стороне генератора, преобразователя на стороне сети, звена постоянного тока с конденсатором.

ВЭУ типа 3 могут иметь достаточно мощный преобразователь на стороне генератора и коммутатор для преодоления провалов напряжения без необходимости шунтирования или отключения преобразователя.

Другие ВЭУ типа 3 включают замыкающее устройство, которое замыкает ротор генератора накоротко при электромагнитных возмущениях и на это время превращает генератор ВЭУ в индукционную машину. 


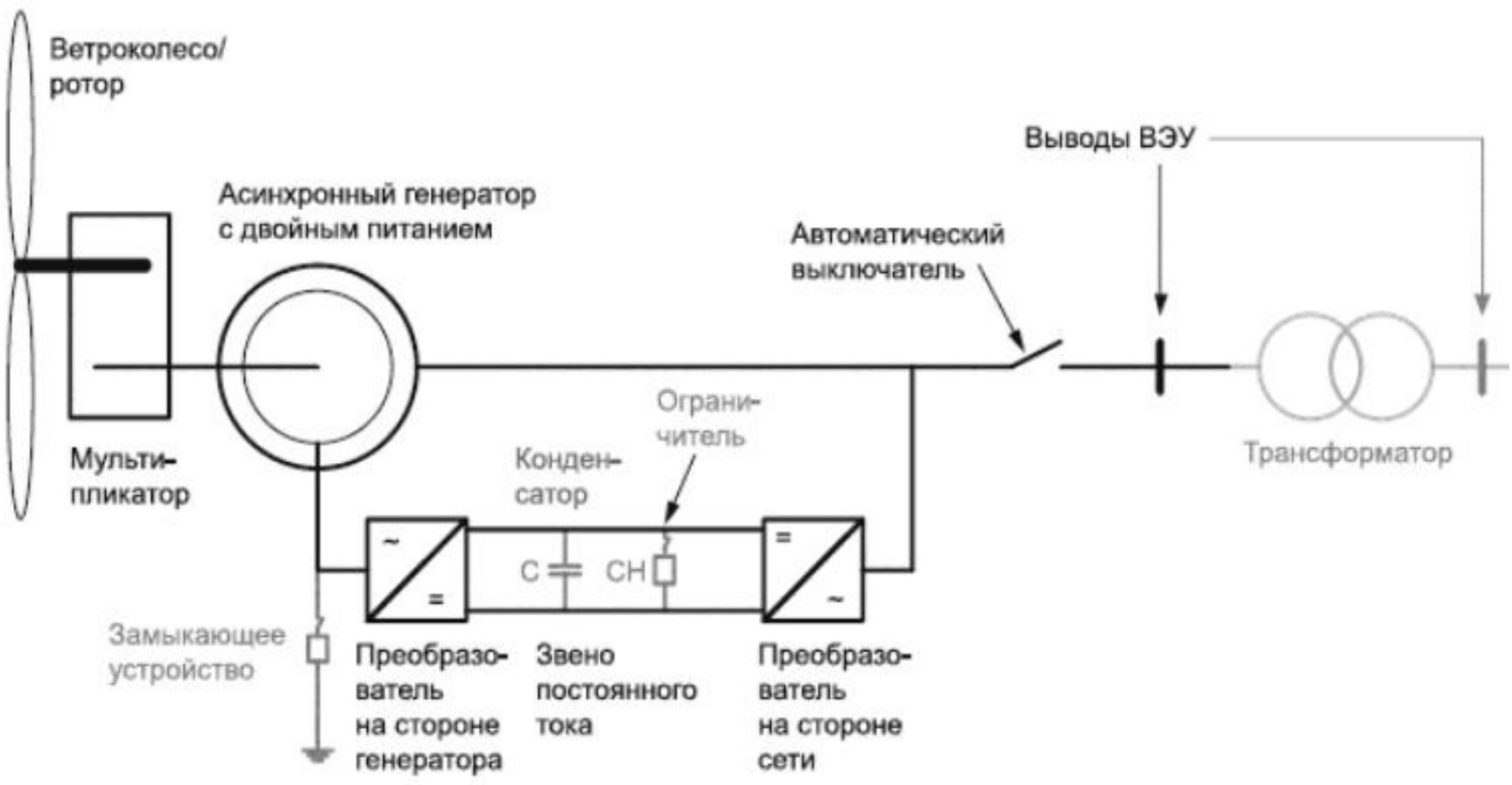

\section{Рис. 10. Электрические и механические компоненты ВЭУ типа 3 [4, с. 22]}

Структура моделей ВЭУ типов 3А и 3В представлена на рис. 11, описание модулей приведено в таблице 6.

Таблица 6

\section{Модули моделей ВЭУ типа 3}

\begin{tabular}{|l|l|}
\hline \multicolumn{1}{|c|}{ Модуль } & \multicolumn{1}{|c|}{ Модели } \\
\hline Аэродинамический & $\begin{array}{l}\text { Двухпараметрическая аэродинамическая модель или } \\
\text { однопараметрическая аэродинамическая модель }\end{array}$ \\
\hline Механический & Двухмассовая модель \\
\hline Генератор & $\begin{array}{l}\text { Модель генератора ВЭУ типа 3А или модель } \\
\text { генератора ВЭУ типа 3В }\end{array}$ \\
\hline Электрооборудование & $\begin{array}{l}\text { Модель автоматического выключателя } \\
\text { (Модель трансформатора) }\end{array}$ \\
\hline Управление & $\begin{array}{l}\text { Модель регулирования активной мощности ВЭУ типа 3 } \\
\text { Модель регулирования реактивной мощности } \\
\text { Модель ограничения тока } \\
\text { Модель ограничения реактивной мощности или } \\
\text { Модель ограничения реактивной и активной мощности } \\
\text { или реактивной мощности и напряжения } \\
\text { Модель управления углом установки лопастей }\end{array}$ \\
\hline Защита электрической сети & Модель защиты электрической сети \\
\hline
\end{tabular}


Структура моделей ВЭУ типов 3А и 3В (рис. 11) включает механический и аэродинамический модули. Модели ВЭУ типов 3А и 3В отличаются моделью модуля генератора, а также для всех ВЭУ типа 3В аэродинамический модуль описывается одномерной аэродинамической моделью.

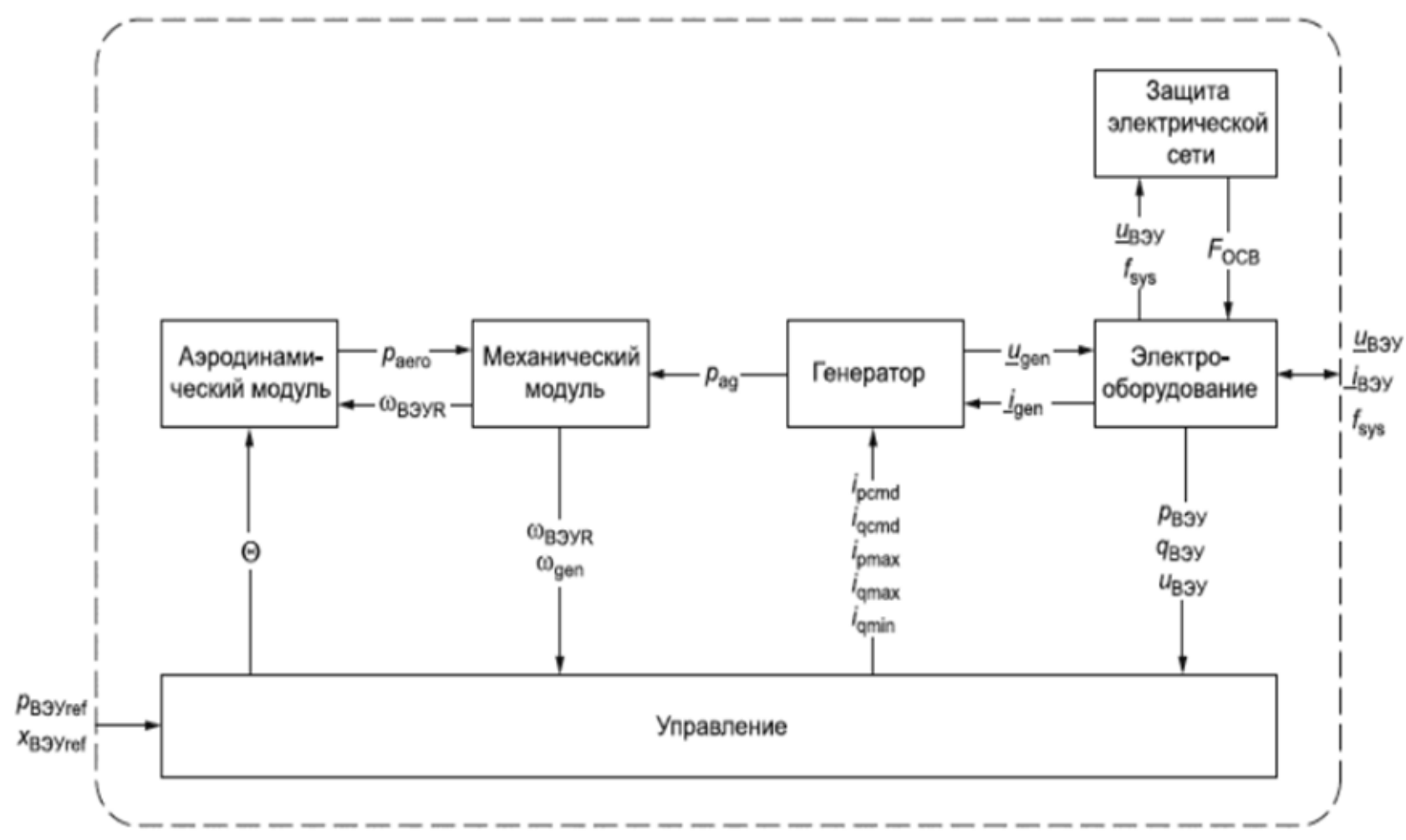

Рис. 11. Структура моделей ВЭУ типов 3А и 3В [4, с.23]

Структурная схема модуля управления для моделей ВЭУ типа 3 показана на рис. 12. 


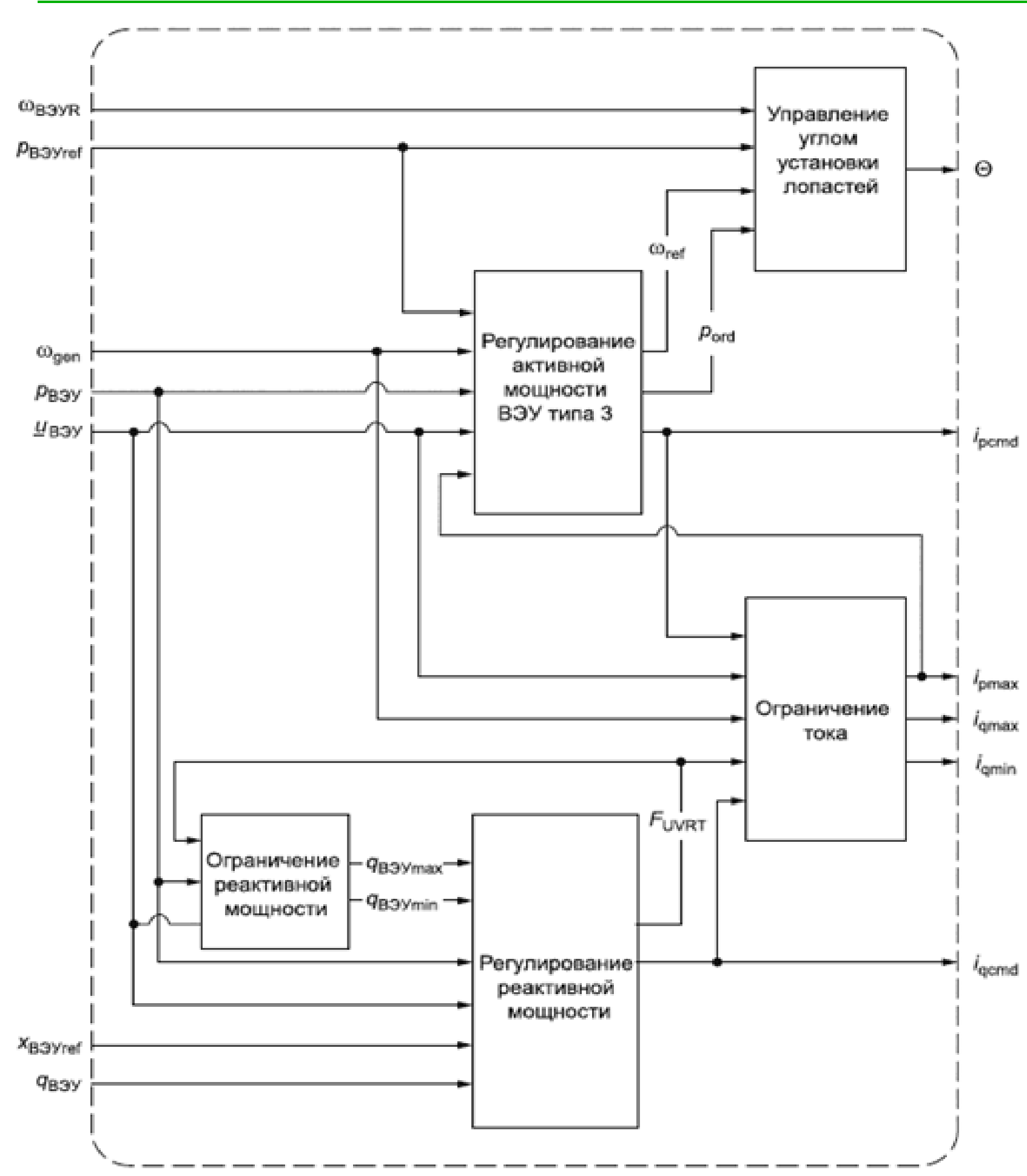

Рис. 12. Структура модуля управления моделей ВЭУ типа 3 с использованием модели ограничения реактивной мощности $[4$, c.24]

Модели ВЭУ типа 4. ВЭУ типа 4 подключают к энергосистеме через преобразователь, рассчитанный на полную мощность ВЭУ. Основные электрические и механические компоненты, включаемые в модели ВЭУ типа 4, показаны на рис.13, где серым цветом обозначены возможные компоненты ВЭУ типа 4. В ВЭУ типа 4 применяют асинхронные или синхронные 
генераторы. В некоторых ВЭУ типа 4 применяют синхронные генераторы с прямым приводом, где отсутствует мультипликатор.

ВЭУ типа 4 с коммутаторами обычно могут быть представлены моделями, в которых отсутствуют аэродинамические или механические модули. ВЭУ без коммутатора порождают послеаварийные колебания мощности, обусловленные крутильными колебаниями.

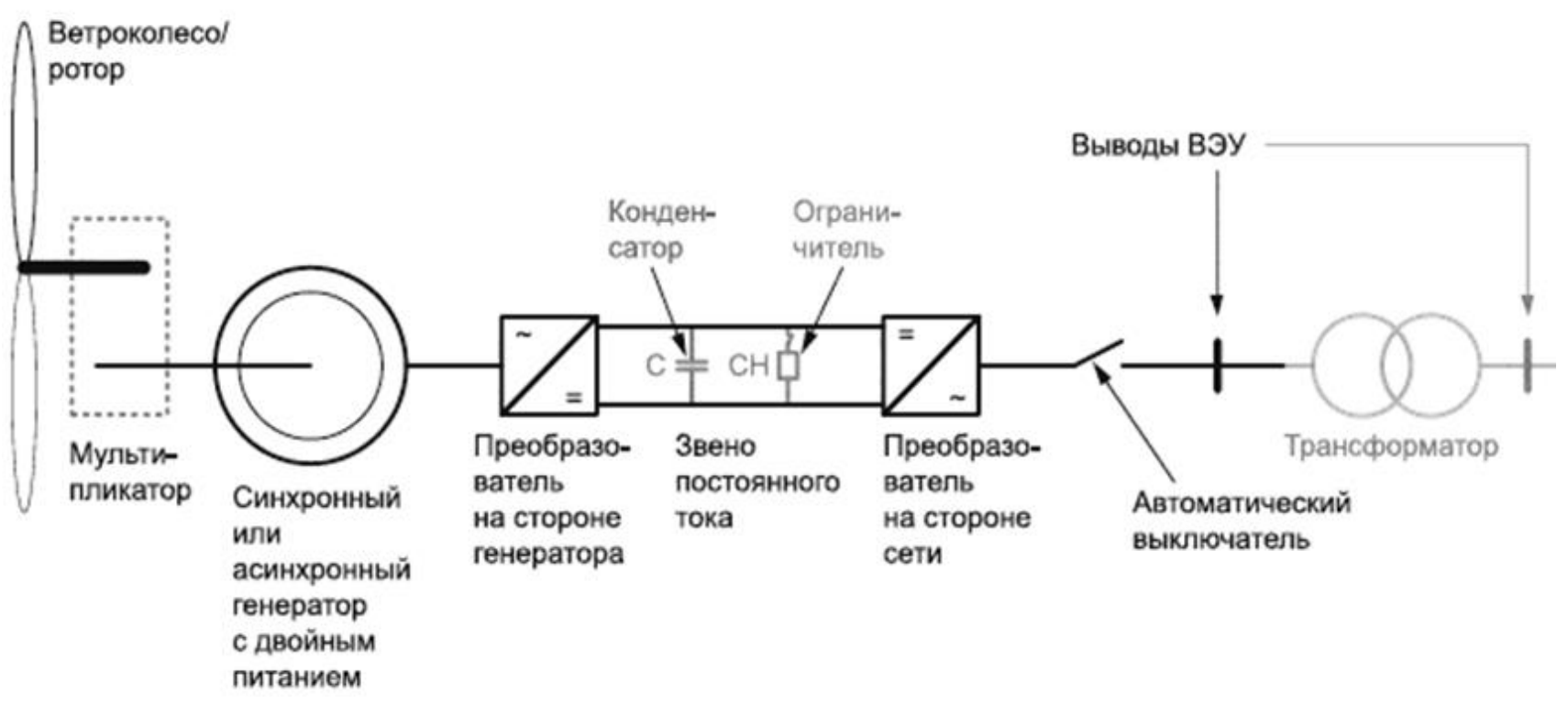

Рис. 13. Электрические и механические компоненты ВЭУ типа 4 [4, с.25]

Это также справедливо для ВЭУ типа 4 с коммутатором, рассчитанным на неполную мощность ВЭУ. Такие колебания мощности обычно не оказывают влияния на устойчивость энергосистемы, однако влияние крутильных колебаний может быть учтено с помощью двухмассовой модели. Если используется коммутатор, то коэффициент затухания колебаний трансмиссии в двухмассовой модели может быть приведен в соответствие с фактическим номиналом коммутатора. Для моделирования ВЭУ типа 4 может использоваться модель ВЭУ типа 3А, однако обычно для представления ВЭУ типа 4 достаточно упрощенных моделей, поскольку преобразователь отделяет ВЭУ от энергосистемы.

Для ВЭУ типа 4 устанавливают две имитационных модели:

- для ВЭУ типа 4А - модель с отсутствующими аэродинамическими и механическими компонентами, с отсутствием учета колебаний мощности;

- для ВЭУ типа 4В - модель с двухмассовой моделью для представления колебаний мощности (аэродинамический момент считается постоянным). 
Структурная схема модели ВЭУ типа 4А показана на рис. 14, а описание модулей модели приведено в таблице 7.

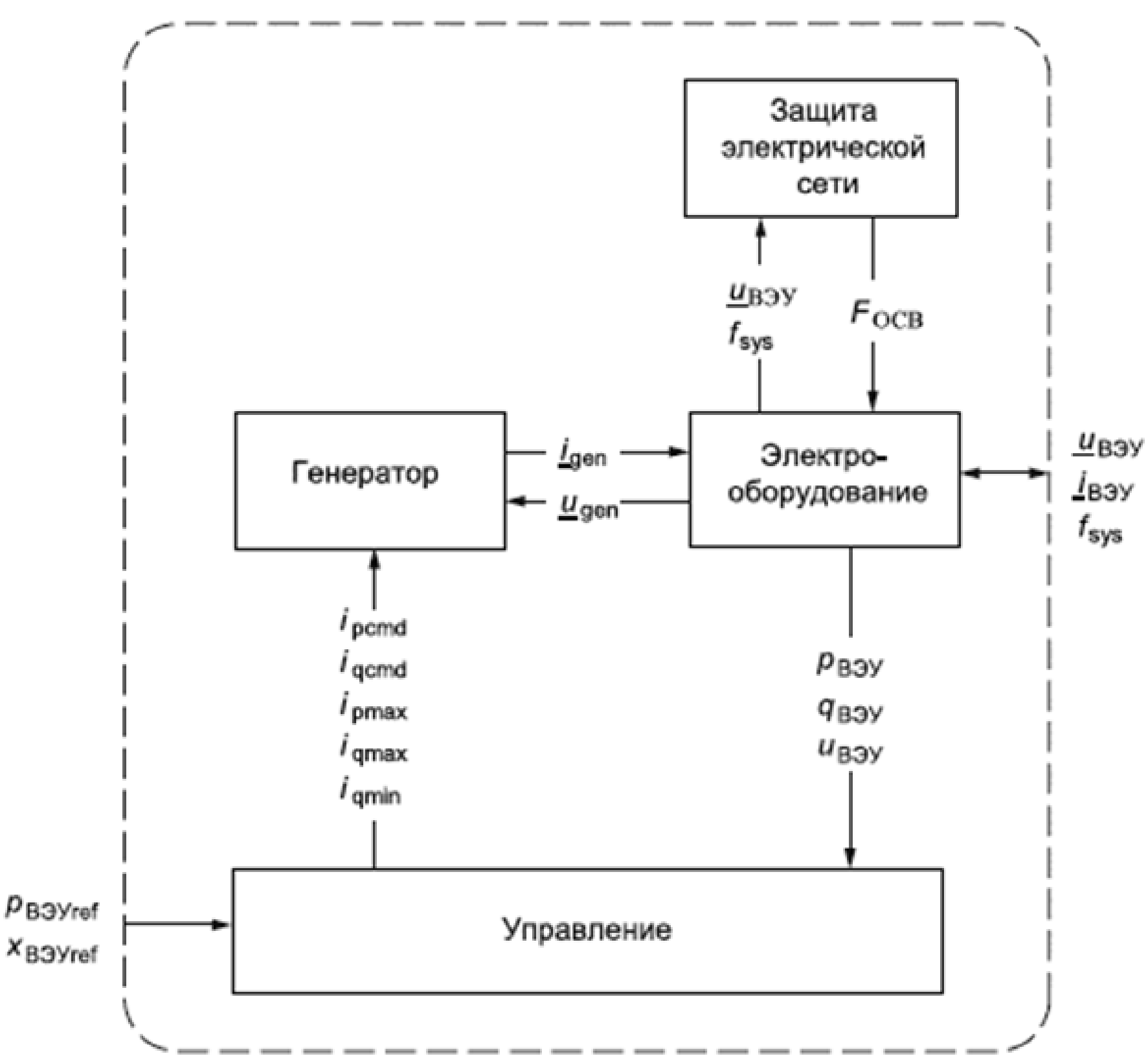

Рис. 14. Структура модели ВЭУ типа 4A [4, с.26] 
Таблица 7

Модули модели ВЭУ типа 4А

\begin{tabular}{|l|l|}
\hline \multicolumn{1}{|c|}{ Модуль } & \multicolumn{1}{c|}{ Модели } \\
\hline Генератор & $\begin{array}{l}\text { Модель генератора ВЭУ типа 4 } \\
\text { (или модель генератора ВЭУ типа 3А) }\end{array}$ \\
\hline Электрооборудование & $\begin{array}{l}\text { Модель автоматического выключателя } \\
\text { (Модель трансформатора) }\end{array}$ \\
\hline Управление & $\begin{array}{l}\text { Модель регулирования активной мощности ВЭУ типа 4A } \\
\text { Модель регулирования реактивной мощности } \\
\text { Модель ограничения тока } \\
\text { Модель ограничения реактивной мощности или } \\
\text { Модель ограничения реактивной и активной мощности } \\
\text { или реактивной мощности и напряжения }\end{array}$ \\
\hline Защита электрической сети & Модель защиты электрической сети \\
\hline
\end{tabular}

В моделях ВЭУ типа 4 может использоваться модель генератора ВЭУ типа $3 \mathrm{~A}$, в которой уменьшается скачок реактивной мощности, появляющийся после восстановления напряжения, и обусловленный в основном численными погрешностями имитации.

Структурная схема модуля управления для моделей ВЭУ типа 4А показана на рис. 15. 


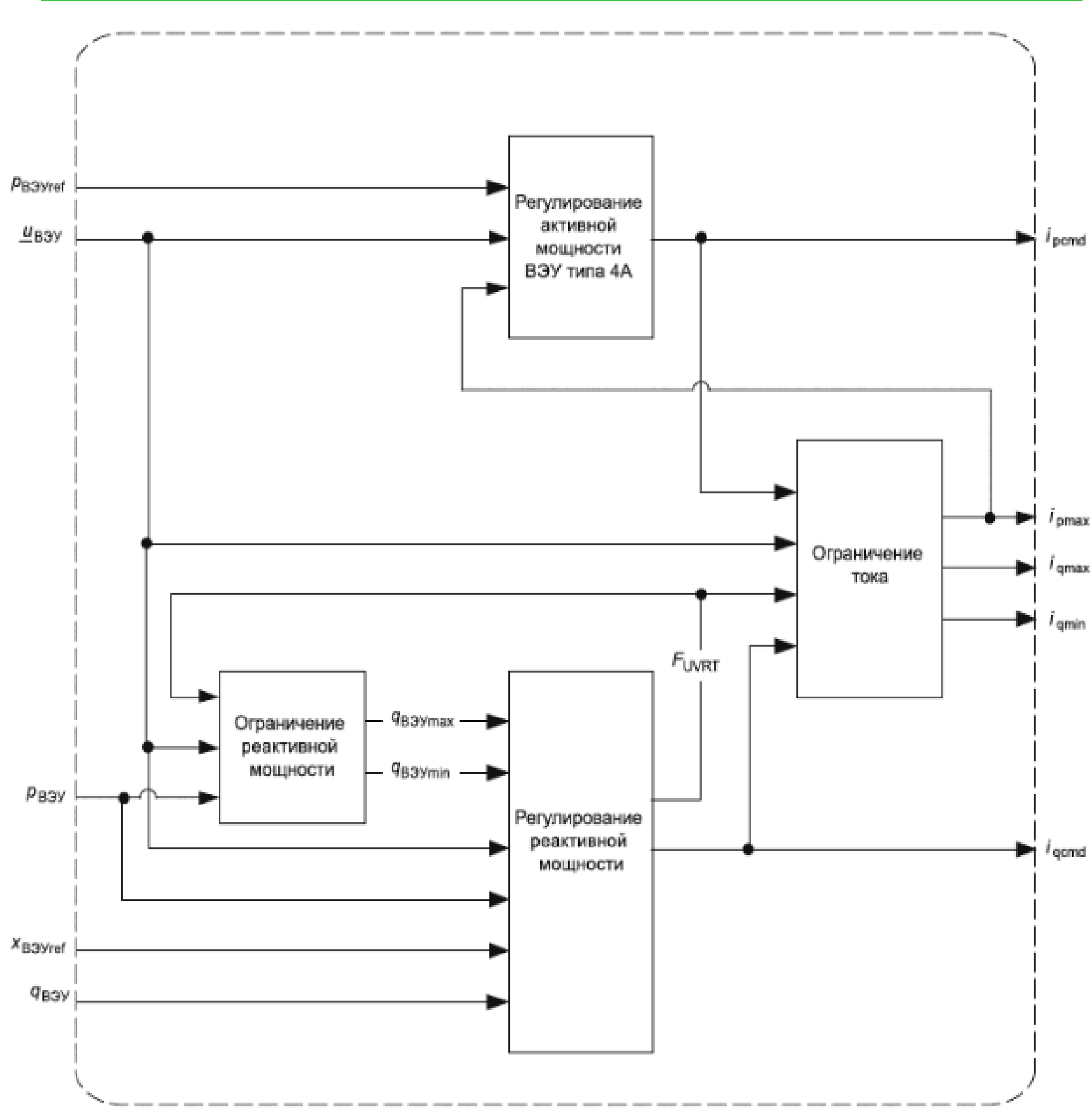

Рис. 15. Структура модуля управления модели ВЭУ типа 4А с использованием модели ограничения

\section{реактивной мощности [4, с.27]}

Структура модели ВЭУ типа 4В показана на рис. 16, а описание модулей модели приведено в таблице 8. 


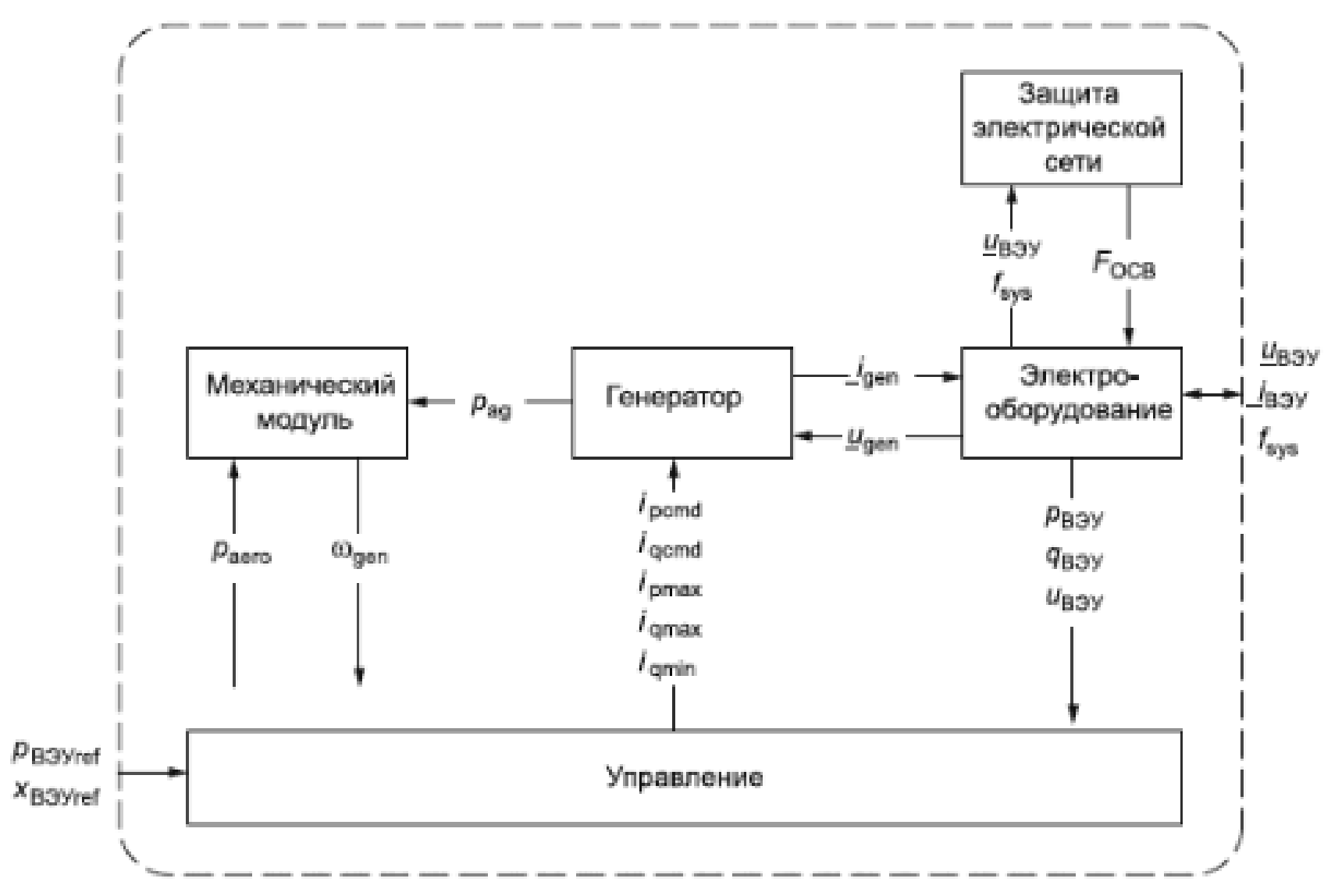

Рис. 16. Структура модели ВЭУ типа 4В [4, с. 28]:

Таблица 8

\section{Модули модели ВЭУ типа 4В}

\begin{tabular}{|l|l|}
\hline \multicolumn{1}{|c|}{ Модуль } & \multicolumn{1}{c|}{ Модели } \\
\hline Механический & Двухмассовая модель \\
\hline Генератор & $\begin{array}{l}\text { Модель генератора ВЭУ типа 4 } \\
\text { (или модель генератора ВЭУ типа 3А) }\end{array}$ \\
\hline Электрооборудование & $\begin{array}{l}\text { Модель автоматического выключателя } \\
\text { (Модель трансформатора) }\end{array}$ \\
\hline Управление & $\begin{array}{l}\text { Модель регулирования активной мощности ВЭУ типа 4В } \\
\text { Модель регулирования реактивной мощности } \\
\text { Модель ограничения тока } \\
\text { Модель ограничения реактивной мощности или } \\
\text { Модель ограничения реактивной и активной } \\
\text { мощности или реактивной мощности и напряжения }\end{array}$ \\
\hline Защита электрической сети & Модель защиты электрической сети \\
\hline
\end{tabular}


Структура модуля управления для моделей ВЭУ типа 4В приведена на рис. 17.

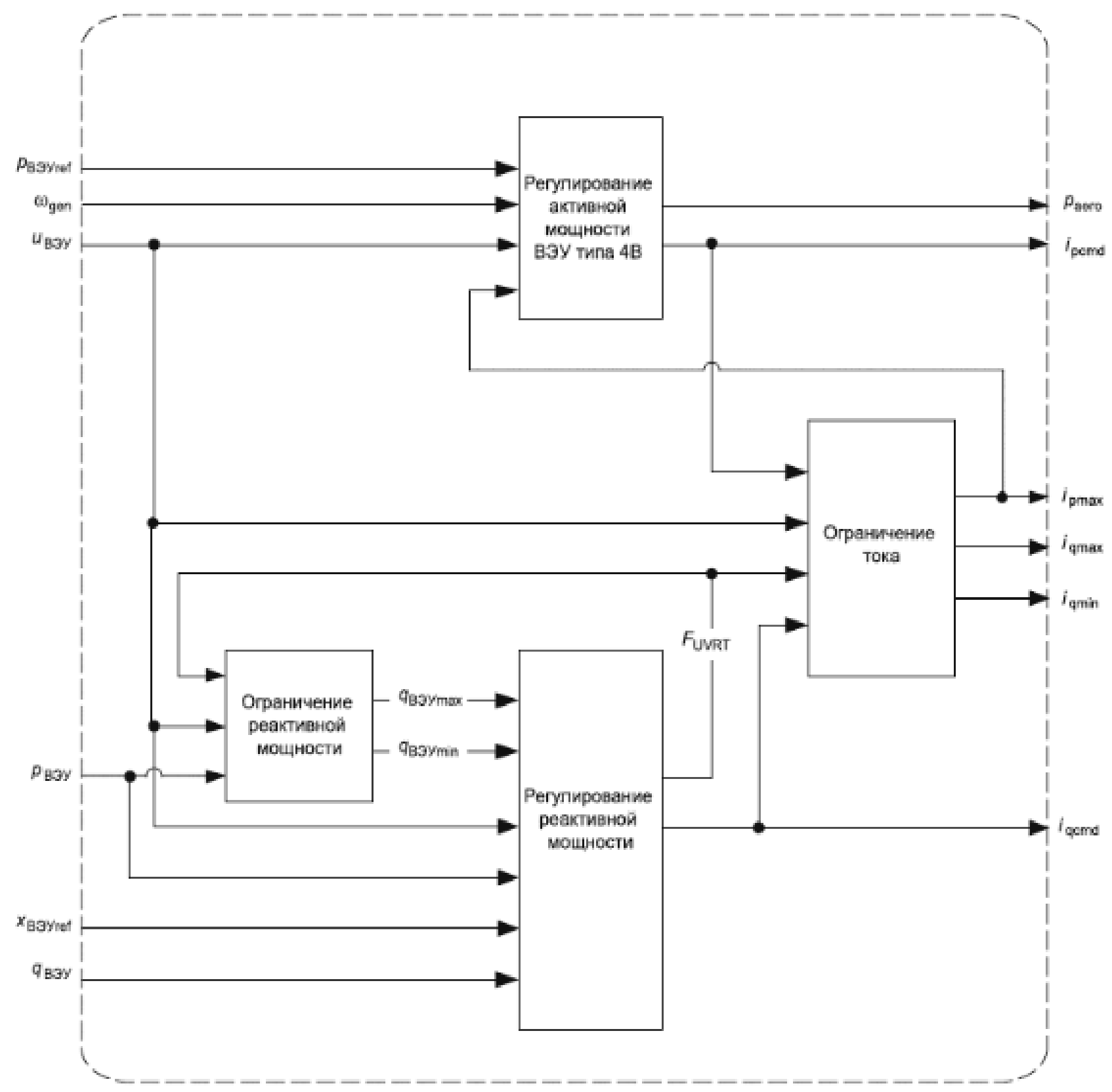

Рис. 17. Структура модуля управления модели ВЭУ типа 4В с использованием модели ограничения реактивной мощности $[4$, с. 29]

Обозначения параметров на структурных схемах имитационных моделей и модулей (см. рис. $5,6,8,9,11,12,14,15,16,17)$ приведены в таблице 9. 


\section{Таблица 9}

\section{Обозначения параметров имитационных моделей ВЭУ}

\begin{tabular}{|c|c|c|}
\hline Обозначение & Наименование & Номера рисунков \\
\hline Paero & Доступная аэродинамическая мощность & Рис. 5, 6, 8, 9, 11, 16, 17 \\
\hline$P_{\mathrm{ag}}$ & Мощность генератора в воздушном зазоре & Рис. 5, 6, 8, 11, 16 \\
\hline$\underline{u}_{\text {Вэу }}$ & $\begin{array}{l}\text { Фазное значение напряжения ВЭУ в координатах } \\
\text { системы }\end{array}$ & $\begin{array}{l}\text { Рис. } 5,6,8,9,11,12,14,15 \text {, } \\
16\end{array}$ \\
\hline$f_{\text {sys }}$ & Частота напряжения в энергосистеме & Рис. 5, 6, 8, 9, 11, 14, 15, 16 \\
\hline ФвЭув & $\begin{array}{l}\text { Угловая скорость вращения ветроколеса (ротора) } \\
\text { ВЭУ }\end{array}$ & Рис. 5, 12 \\
\hline$\omega_{\text {gen }}$ & Угловая скорость вращения генератора & Рис. 5, 6, 8, 11, 12, 16, 17 \\
\hline$\underline{u}_{\text {gen }}$ & $\begin{array}{l}\text { Фазное значение напряжения генератора } \\
\text { в координатах системы питания }\end{array}$ & Рис. 5, 6, 8, 9, 11, 14, 15, 16 \\
\hline$\underline{i}_{\text {gen }}$ & $\begin{array}{l}\text { Фазное значение тока генератора в координатах } \\
\text { системы питания }\end{array}$ & Рис. 5, 6, 8, 11, 14, 15, 16 \\
\hline$F_{\text {осв }}$ & Отключение сетевого выключателя & Рис. 5, 6, 11, 14, 15, 16 \\
\hline$U_{\text {Вэу }}$ & Напряжение ВЭУ & Рис. $6,8,11,14,15,16,17$ \\
\hline$i_{\text {ВЭу }}$ & Ток ВЭУ & Рис. $6,8,11,14,15,16$ \\
\hline$P_{\text {Вэу }}$ & Активная мощность ВЭУ & $\begin{array}{l}\text { Pис. } 8,9,11,12,14,15,16 \text {, } \\
17\end{array}$ \\
\hline$q_{\text {вЭу }}$ & Реактивная мощность ВЭУ & Рис. $11,12,14,15,16,17$ \\
\hline$r_{\text {rot }}$ & $\begin{array}{l}\text { Активное сопротивление ротора асинхронного } \\
\text { генератора с переменным сопротивлением ротора }\end{array}$ & Рис. 9 \\
\hline$i_{\mathrm{pcmd}}$ & Уставка генератора по активному току & Рис. 11, 12, 14, 15, 16, 17 \\
\hline$i_{\mathrm{qcmd}}$ & уставка генератора по реактивному току & Рис. $11,12,14,15,16,17$ \\
\hline$i_{\mathrm{pmax}}$ & Максимальный генерируемый активный ток & Рис. $11,12,14,15,16,17$ \\
\hline$i_{\mathrm{qmax}}$ & Максимальный генерируемый реактивный ток & Рис. $11,12,14,15,16,17$ \\
\hline$i_{\mathrm{qmin}}$ & Минимальный генерируемый реактивный ток & Рис. 11, 12, 14, 15, 16, 17 \\
\hline$P_{\text {ВЭу ref }}$ & Опорная активная мощность ВЭУ & Рис. $12,14,15,17$ \\
\hline$q_{\text {ВЭУ ref }}$ & Опорная реактивная мощность ВЭУ & Рис. 12 \\
\hline$\Theta$ & Угол установки лопастей & Рис. 12,16 \\
\hline$\omega_{\text {ref }}$ & Опорная угловая скорость ВЭУ & Рис. 12 \\
\hline$P_{\text {ord }}$ & $\begin{array}{l}\text { Сигнал уровня активной или реактивной мощности, } \\
\text { заданный регулятором ВЭУ }\end{array}$ & Рис. 12 \\
\hline$F_{\text {UVRT }}$ & Сигнал провала напряжения & Рис. 12,17 \\
\hline$q_{\text {ВЭУ } \max }$ & $\begin{array}{l}\text { Максимальная генерируемая реактивная мощность } \\
\text { ВЭУ }\end{array}$ & Рис. 12, 17 \\
\hline$q_{\text {ВЭУmin }}$ & $\begin{array}{l}\text { Минимальная генерируемая реактивная мощность } \\
\text { ВЭУ }\end{array}$ & Рис. 12, 17 \\
\hline$x_{\text {ВЭУref }}$ & $\begin{array}{l}\text { Опорная реактивная мощность ВЭУ или опорное } \\
\text { напряжение в зависимости от режима } \\
\text { регулирования, } \mathrm{P}_{\text {ном }} \text { или } \mathrm{U}_{\text {ном }}\end{array}$ & Рис. 12, 14, 15, 17 \\
\hline
\end{tabular}




\section{Заключение}

В результате проведенного исследования определены области использования обобщенных имитационных моделей ветроэнергетических установок (ВЭУ), присоединенных к энергосистеме.

Обобщенные имитационные модели ВЭУ предназначены для исследования поведения энергосистемы в переходных режимах с определением характеристик прямой последовательности основной частоты, равной 50 Гц.

Имитационные модели предназначены для исследования синхронных режимов работы ВЭУ с ВЭС и энергосистемой и не предназначены для исследования явлений, происходящих в процессе самосинхронизации до достижения полной синхронизации работы ВЭУ, ВЭС и энергосистемы.

Модели применимы только к ВЭУ, поэтому не включают средства управления уровня ВЭС или такого дополнительного оборудования, как статические компенсаторы (SVC, STATCOM) и другие устройства, моделирование которых отнесено к моделированию ВЭС.

Моделирование взаимодействия ВЭУ с устройствами управления ВЭС также отнесено к моделированию ВЭС и не включено в модели, описанные в статье.

Имитационные модели ветроэнергетических установок (ВЭУ), присоединенных к энергосистеме, являются основой для построения общих динамических имитационных моделей ВЭС.

Имитационные модели ВЭУ имеют модульную структуру, что позволяет проводить их необходимую доработку в случае появления новых технологий или новых способов управления.

В соответствии с требованиями ГОСТ Р 54418.27.1 для любых моделей ВЭУ, предназначенных для определения характеристик прямой последовательности основной частоты, предусмотрена проверка реакции модели на провалы напряжения, на пошаговые изменения опорных значений и проверка функционирования модели защиты электрической сети.

\section{Список литературы}

1. ГОСТ Р 51237-98 Нетрадиционная энергетика. Ветроэнергетика. Термины и определения. Введ. 01.07.1999; акт. 01.01.2021. - Москва: ГОССТАНДАРТ РОССИИ, 1999. - 16 с. 
2. ГОСТ P 55589-2013 (МЭК 60050-415:2999) Международный электротехнический словарь. Часть 415. Установки ветроэнергетические. Системы генерирования электроэнергии. Введ. 01.07.2014; акт. 01.01.2021. Москва: Стандартинформ, 2014. - 20 с.

3. ГОСТ Р 54418.1-2012 (МЭК 61400 -1:2005) Возобновляемая энергетика. Ветроэнергетика. Установки ветроэнергетические. Часть 1 . Технические требования. Введ. 20.09.2012. - Москва: Стандартинформ, 2016. $-88 \mathrm{c}$.

4. ГОСТ Р 54418.27.1-2019 (МЭК 61400-27-1:2015) Возобновляемая энергетика. Ветроэнергетика. Установки ветроэнергетические. Часть 27-1. Общие имитационные модели ветроэнергетических установок, присоединенных к энергосистеме. Введ. 01.06.2020; акт. 01.01.2021. - Москва: Стандартинформ, 2020. - 99 с.

5. ГОСТ Р 54418.21-2019 (МЭК 61400-21:2008) Возобновляемая энергетика. Ветроэнергетика. Установки ветроэнергетические. Часть 21. Измерение и оценка характеристик, связанных с качеством электрической энергии, ветроэнергетических установок, подключенных к электрической сети. Введ. 28.09.2011; акт. 01.01.2021. - Москва: Стандартинформ, 2012. - 50 с.

(C) Л.П. Андрианова, Э.Р. Байбурин, 2021 